\title{
IMPACTO DE LOS PARADIGMAS PEDAGÓGICOS HISTÓRICOS EN LAS PRÁCTICAS EDUCATIVAS CONTEMPORÁNEAS
}

\author{
Mario César Zaccagnini \\ Investigador del Grupo G.I.S.E.A. (U.N.M.D.P.), Argentina \\ Asesora: María Dolores Jolis
}

\section{INTRODUCCIÓN: EL PORQUÉ DE LOS PARADIGMAS HISTÓRICOS}

El tema que nos ocupa en este trabajo, el de los paradigmas pedagógicos de formación docente, reviste una gran importancia a la hora de pensar acerca de la identidad del rol profesional docente; en efecto, la epistemología de la formación docente se nutre, entre otros, de elementos constitutivos de la la construcción del "Hábitus docente" y que definen la naturaleza de su quehacer concreto en la institución educativa. En este caso, cobran relevancia los compromisos que se asumen en toda formación profesional y la historia incorporada durante la misma. Así, las tradiciones imperantes en la formación docente atesoran una crucial importancia ya que, como productos del devenir histórico, están presentes en las imágenes sociales, en la dinámica de las decisiones políticas, en los imaginarios que imbrican la trama de las organizaciones educativas y la propia conciencia de los docentes. Asimismo, el contexto socio-político, que configura a la labor profesional del docente (esto es, las relaciones entre el control social y la autonomía en el trabajo docente), resulta de vital importancia a la hora de analizar las condiciones reales en que se desenvuelven las prácticas.

Al pensar en abordar la cuestión de la identidad del rol desde la perspectiva de los paradigmas históricos de formación, surgen interrogantes que planteados, nos brindan puntos de partida; al efecto, es conveniente destacar la siguiente cita de Terigi y Diker (1997, p.25):

\begin{abstract}
¿Cómo transformar la escuela moderna concebida hace trescientos años, en una institución que responda a las necesidades de un mundo globalizado, de una cultura massmediática, de unos niños que sobre muchas cosas saben más que nosotros, de un mercado de trabajo flexibilizado cuyas demandas formativas mutan constantemente? ¿Cómo respetar las diferencias culturales a través de una institución cuya estructura es profundamente homogeneizante? ¿Cómo formar para el ejercicio ciudadano en la era de la política mediática, de la postpolítica? ¿Cómo confiar en el sentido de lo que enseñam os si las certezas científicas y la confianza ilustrada en el progreso indefinido del conocimiento están profundamente cuestionadas?
\end{abstract}

En otro orden, al revisar críticamente dichos pararadigmas históricos y demostrar que de alguna manera mantienen una inusitada vigencia en la configuración de las prácticas educativas, nos estamos aventurando en el abordaje crítico de los aspectos ideológicos que interpelan el rol social de la escuela y que por ende, configuran al espacio simbólico de la profesión docente. Las concepciones educativas que cada paradigma dio a luz en su momento, definiera a un determinado sujeto pedagógico; entendido éste como la relación compleja entre el educador y el educando, producto de la vinculación compleja entre ambos actores sociales. El quehacer educativo, como todo trabajo, se inscribe en un marco legitimador que le confiere una determinada legalidad. Dicha legitimación es configurada a partir de unas determinadas relaciones de poder, entre los distintos grupos que entretejen la trama social. Por ello, todo paradigma 
pedagógico define su sujeto y es a partir de la misma en cómo se concibe el rol del educador. (Puigros, 1990).

Por ello, abordar la temática del sujeto pedagógico en su posibles configuraciones históricas, nos propone aventurarnos en el vasto y complejo territorio de las representaciones que sustentan a las prácticas educativas. Se entiende a éstas no solo en su limitada circunscripción al ámbito institucional de la escuela sino que se definen como una de las estrategias privilegiadas de las cuales, la sociedad se vale para la transmisión del corpus de saberes y conocimientos culturalmente válidos a las jóvenes generaciones.

Ampliando el concepto, toda práctica educativa es en sí productora de sujetos a partir de otros sujetos, es decir, se trata de una mediación. Se realiza construyendo un sujeto mediador, que se ha de denominar como sujeto pedagógico. El mismo define a la relación compleja entre educador y educando, a la resultante de la vinculación entre ambos que participan en las complejas situaciones educativas. Estas situaciones tienen lugar en distintos ámbitos institucionales, que encuadran y precisan una pedagogía. $Y$ toda pedagogía define su sujeto; cada una estipula los elementos y el orden de las series que la constituyen como estructura significante, cuya función es mediar entre los sujetos políticos y sociales, y el habitus que se pretende inculcar. En este sentido, se considera como pertinente, el concepto de sujeto pedagógico que plantea Adriana Puigrós (1990); el cual define que todo sujeto se constituye en una relación, en la que participan el educador, el educando, el habitus y los conocimientos que se transmiten, ubicados en un momento y un tiempo histórico determinado.

El sujeto pedagógico histórico definido por la institución escolar es un sujeto pedagógico universal, ya que el dispositivo pedagógico-didáctico estandariza las previsiones acerca de qué, cómo y cuando debe aprender el conjunto de niños agrupados en niveles. Es así como se ignoran las diferencias de capital cultural, las trayectorias de vida relacionadas con el lugar que se ocupa en la estructura social, historias vitales particulares, motivaciones, intereses, etc. Hoy por hoy, se debe considerar al sujeto pedagógico desde una perspectiva más amplia multirreferenciada, en un intento de acercarse a la complejidad del universo sociocultural, al que desafía con la dispersión del sujeto pedagógico universal, al cual es posible definir como las múltiples articulaciones posibles entre el educador, el educando y los saberes y la configuración de espacios educativos con su propia legitimidad pedagógica.

En efecto, además de los espacios institucionales como la familia y la escuela considerados como espacios socializadores tradicionales, actualmente el universo que conforman las instituciones, cuentan con un espacio no adscrito a los lineamientos institucionales tradicionales pero que tiene una creciente y espectacular gravitación en el comportamiento colectivo e individual de los sujetos: el ámbito sociocultural definido por lo que genéricamente se conoce como sociedad global y cultura de masas. Esta nueva configuración sociocultural, de construcción histórica, se ha convertido en hegemónica a partir de la última revolución tecnológica, cuyos protagonistas son las denominadas nuevas tecnologías de la comunicación y la información.

En este nuevo escenario, se habla de un espacio socializador virtual, simultáneo y paralelo a la acción pedagógica de las prácticas educativas familiares y escolares, definido por los medios masivos de 
comunicación. En particular, la revolución de la comunicación, ha impactado profundamente en la vida social, redimensionando en especial las configuraciones comunicacionales con su consecuente impacto en las relaciones sociales.

Los conceptos de postmodernidad, globalización y aculturación virtual (Jolis y Manghi, 2001), son cruciales para comprender los procesos de transformación sociocultural que estamos viviendo. La postmodernidad implica, en una perspectiva paradigmática, el surgimiento de nuevas condiciones sociales y culturales que precipita un proceso de crisis atravesando las identidades individuales y sociales y las distintas dimensiones que conforman la esfera de las ideologías. Es así como la postmodernidad ha empujado a una redefinición de todo el sistema de valores que configuraban las concepciones del mundo moderno.

Las nuevas tecnologías pusieron en marcha procesos que incidieron decisivamente en la vida de los sujetos, dando lugar a la denominada "sociedad de la información". No obstante, diversos espacios institucionales prosiguen estructurados bajo las categorías del orden sociocultural pretérito; por ejemplo, las prácticas educativas en la institución escolar. Basta solo echar una mirada a la dimensión pedagógica de la enseñanza de la lengua, en la cual el dispositivo pedagógico escolar concibió y circunscribió el conocimiento y adquisición de la lecto-escritura a una sola forma. Actualmente, se sabe que la misma es solo una de sus versiones posibles y que el contexto comunicacional a disposición es mucho más complejo que el prototípico del modelo social fundador de la cultura escolar.

Es claro que la escuela es una institución de matriz propia de la Sociedad Moderna, donde la escritura se difunde bajo una sola forma y es la de adquisición, dominio y uso del conocimiento puesto en juego exclusivamente en el marco de la escolarización. Tradicionalmente, los procesos educacionales revelan maneras formales de comunicación a través de las cuales se transmiten conocimientos mediados por espacios institucionales como la familia, la escuela y otras instituciones, que establecen y delimitan un universo cultural. En cambio, los procesos de comunicación puestos en juego a través de de los medios masivos de comunicación, operan simultáneamente sobre configuraciones de sentido en permanente expansión: la digitalización de la palabra cambia el soporte de lo escrito y los modos de acceso porque se hace circular un tipo de escritura no secuencial, la informatización posibilita la administración de múltiples fuentes de referencia y una activa intervención del usuario.

Los nuevas generaciones se encuentran lejos de constituirse en los referentes reales de una legalidad pedagógica que interpelaba a los sujetos concebidos como un prototipo de conformidad disciplinada; los docentes que hoy ejercen la labor educativa en las escuelas son personas que discurrieron su escolarización en un marco de consenso que aseveraba el valor positivo de la escuela, como la construcción de una sociabilidad optimista y próspera. Los alumnos que hoy pueblan la escuela rechazan este postulado mediante diversas modalidades de resistencia al mismo.

Uno de los más graves problemas es que los docentes continúan formándose bajo los mismos preceptos que alimentaron los marcos epistemológicos, conceptuales y metodológicos históricos del "abc" de la tarea docente; es decir, se hace referencia a la vigencia de las tradiciones que forjaron las matrices de 
la formación profesional docente. Basta con nombrar a tres de ellas, que continúan perviviendo y gravitando en la construcción del "habitus profesional": la normalista que define el ser maestro como una sujeto ejemplar y ejemplificador; a partir de esta representación se concibe a la docencia como un apostolado, los docentes hoy en ejercicio se formaron en este marco paradigmático. Otra es aquella en donde se pone énfasis en la adquisición y desarrollo de saberes instrumentales; se trata de la tradición técnica que pone en evidencia el quiebre entre la teoría y la práctica educativa. Esta tradición concibe a los docentes como técnicos cuya misión es la de ejecutar estrategias didácticas que pongan en juego los conocimientos prescriptos curricularmente por los expertos, a los efectos de que los alumnos adquieran saberes, contextualizados en sistemas conceptuales cerrados. La tercera tradición aludida, desplaza a la formación pedagógica a un segundo plano; la tradición académica tuvo y tiene un fuerte arraigo en las universidades, las instituciones universitarias de formación docente son pensadas como circuitos educativos con una calidad educativa diferenciada pero que en la práctica, observan serios problemas de articulación didáctica con el contexto escolar. En concreto, en las prácticas educativas estas tradiciones aparecen entretejidas entre sí, y su análisis desconstructivo facilitaría comprender las características del quehacer profesional docente actual.

Hoy no es posible hablar de un sujeto pedagógico universal, tal como se lo concebía a partir del discurso educativo hegemónico de la institución escolar en el contexto de la modernidad, es necesario considerar que hay que hablar de un sujeto pedagógico disperso, que adquiere nuevas configuraciones, signadas por diversas significaciones de acuerdo a la legalidad pedagógica de los espacios institucionales que interpelan al individuo. La escuela, la familia y el universo mediático, constituyen tres de los más importantes espacios donde se ensayan con diferentes resultados en términos de eficacia, prototipos de sujetos pedagógicos.

\section{LOS MODELOS DE FORMACIÓN DOCENTE: RE-DESCUBRIENDO LAS TRADICIONES}

Emprendamoa ahora, el recorrido del largo sendero trazado por los paradigmas que tuvieron decisiva gravitación en la educación formadora de los docentes en la Argentina, destacando en primera instancia el contexto sociopolítico que los alumbró, identificando los elementos psicosociales que constituyeron su universo simbólico; en segunda instancia, se detallan los elementos epistemológicos, conceptuales y metodológicos de los paradigmas analizados, como ser: tesis o núcleo paradigmático, base filosófica, base histórico-social, base psicológica, modelo didáctico (para qué enseñar, qué enseñar, cómo enseñar, relación alumno-docente, evaluación). Solo analizaremos aquellos que incideron hegemónicamente en la configuración pedagógico-didáctica del campo de las prácticas educativas. 


\title{
El paradigma normalizador
}

Si pensamos por unos momentos en las escenas que pueblan la cotidianeidad de la institución educativa, es posible que podamos observar una serie de códigos, rituales, procedimientos característicos que remiten inmediatamente a su análisis a partir del concepto de representación social. Si tal como se ha planteado en el apartado anterior en que se conciben a las mismas como verdaderas construcciones simbólicas, enmarcadas estructural y dinámicamente en el devenir histórico de una sociedad, estos elementos constituyen lo que comúnmente se denomina sistemas sociales de valores, ideas y procedimientos.

El hábitus docente es patente a la hora de observar con detenimiento la realidad institucional escolar: basta solo escuchar las muletillas y frases hechas que pueblan el universo lingüístico de buena parte de maestros y profesores como para darse cuenta de ello. Estos elementos discursivos son los encargados de permitir a los sujetos miembros de una organización, como es en este caso la escuela, compartir un corpus compuesto por imágenes y modelos explicativos, desde los cuales se decodifican e interpretan los sucesos, hechos y circunstancias de la vida cotidiana: Es decir, componen lo que ordinariamente se denomina pensamiento práctico.

Cada uno de los actores del hecho educativo, en este caso los docentes, constituyen un punto de llegada de un largo camino trazado a partir de sus experiencias institucionales, contextualizadas en el marco de determinadas tradiciones, asimiladas analógicamente al concepto de representación social. Dichas tradiciones interesan en la medida que permiten el análisis de la práctica educativa en la perspectiva de los universos simbólicos hegemónicos que nutren los modelos de la formación profesional del docente.

En las investigaciones actuales, se concibe a las tradiciones en la formación docente como estructuraciones del pensamiento conceptual y práctico, que formalizan un modo de concebir a la práctica educativa. En este sentido, se toma nota a lo que plantea Davini (1995, p.20) cuando define el término tradición:

\begin{abstract}
Entendemos por tradiciones en la formación de los docentes a configuraciones de pensamiento y de acción que, construidas históricamente, se mantienen a lo largo del tiempo, en cuanto están institucionalizadas, incorporadas a las prácticas y a la conciencia de los sujetos. Esto es que, más allá del momento histórico que como matriz de origen las acuñó, sobreviven actualmente en la organización, en el currículum, en las prácticas y en los modos de percibir de los sujetos, orientando toda una gama de acciones.
\end{abstract}

Como resultantes de una larga historia signada por las tensiones y conflictos manifiestos entre los diversos actores y grupos del campo educativo, que lejos de una pretendida homogeneidad se caracteriza por ser un espacio de agudas contradicciones ideológicas; las tradiciones pedagógicas perviven en la actualidad, incidiendo con significativa gravitación en el debate educativo cotidiano. A nadie escapa las sentencias y juicios que muchos docentes en la vida cotidiana escolar, expresan para explicar las vicisitudes de su práctica, que remiten a concepciones acerca del aprender y enseñar propias de marcos socio-psicopedagógicos ya considerados superados. Como si los aportes de la ciencia de las últimas décadas (la psicología, la sociología, la didáctica, etc.) y los profundos cambios que la propia realidad social 
experimentó (influyendo decididamente en toda realidad institucional), no hubieran incidido lo suficiente para transformar los conocimientos pedagógicos.

Así es como se observa lo relativamente impermeable y resistente que resulta el discurso pedagógico en la legitimación de la práctica educativa, co-existiendo en el mismo ideas a tono con los tiempos actuales con concepciones tradicionales de fuerte gravitación a la hora de confirmar el marco referencial desde donde se apoya la labor educativa. Esta co-existencia no determina que las nuevas ideas tengan la suficiente fuerza para ser convenientemente significativas a la hora de facilitar un cambio de rumbo. Por el contrario, si de tradiciones se trata, se está ante la supervivencia de imágenes sociales que representan un modo de concebir al ser docente y una forma de ejercer la práctica concreta en la institución (Davini, 1995).

Las luchas que signaron el campo pedagógico a lo largo del siglo XX, desde la mirada de los sectores más progresistas en su intento de poner al día a la práctica educativa, no han demostrado hasta la fecha, tener la suficiente fuerza para vencer el amurallamiento conservador, forjado por las tradiciones. Hoy, reforma educativa mediante, es dable encontrar un discurso inundado con la terminología conceptual y técnica de los marcos teóricos en que abrevan los vientos renovadores del campo pedagógico, pero terminan estrellándose contra la murallas del fracaso: frente a la devastación resultante del modelo de ajuste neoliberal el colectivo docente se muestra inmerso en la decepción y en la incertidumbre.

Entonces, al abordar el tema de las tradiciones, como ellas parecen reactualizarse en el día a día de las prácticas educativas, es dable pensar que se está frente a una auténtica cultura, la cultura escolar, concebida como una densa trama imbricada con valores, conocimientos y saberes, normas, fórmulas y esquemas de procedimientos, etc. Por diversas razones, tanto intrínsecas como extrínsecas al sistema, la cultura escolar se ha demostrado como más resistente, más conservadora frente a los cambios, que otros ámbitos de producción cultural (Caruso y Dusel, 1995). Es posible identificar algunos factores, rastreando en la historia de las tradiciones de la formación docente, que faciliten el análisis de esta particularidad del universo escolar.

Posicionándonos en el contexto histórico en que surge la educación formal masiva, pública, gratuita y obligatoria, nos encontramos con una Argentina cerrando un sangriento ciclo de su historia, signado por más de cincuenta años de guerras civiles, que trata de darse un ordenamiento jurídico y político a tono con los vientos de la apabullante modernidad de la sociedad capitalista, en pleno auge en Europa y Estados Unidos y que amenaza con expandirse por todos los rincones del mundo. Una de los pilares que imprimen la coloración del nuevo paradigma cultural del universo capitalista, lo constituye el positivismo como corriente epistemológica que domina y configura el universo simbólico de las nuevas sociedades que se transforman al compás de la consigna "Orden y Progreso". El racionalismo cartesiano, a su vez, constituye una de las columnas vertebrales centrales del positivismo, desde el cual se enarbola el manifiesto sustantivo: "solo razón conduce a la verdad y que la verdadera naturaleza del pecado es la ignorancia"; por lo cual, aparece el Estado como garante de que los sujetos sean ilustrados en la razón que los llevará a la verdad (Martiña, 1989). 
Para el nuevo orden de la sociedad capitalista, la condición de iletrados en se encontraba la gran mayoría de la población, constituía un obstáculo insalvable para sus objetivos económicos. Asimismo, la educación fundamentalmente pasa a constituirse un espacio disciplinador para los nuevos "invitados" que se vuelcan masivamente del campo a la ciudad; estos sujetos son portadores de hábitos y costumbre no deseados para el nuevo sujeto que necesito fundamentalmente en el mundo del trabajo y la producción.

En el caso de la Argentina, una generación de hombres inspirados en el pogresismo positivista hegemónico, traza y ponen en ejecución un proyecto de modernización, que trata de ubicarlo en el nuevo orden internacional. Hablamos lógicamente de la Generación del '80. En ese marco nace el universo escolar que todos conocemos con un objetivo claro: construir y dar identidad al ciudadano argentino; hay que civilizar la barbarie propia de nuestra tierra y la que viene en los barcos desde la lejana Europa. Este objetivo de disciplinamiento, se lo debe buscar fundamentalmente en el proyecto socio-político de la clase dominante de la época, en el contexto de estratificación social reinante en la Argentina. Puigrós (1990, p.98), lo sintetiza de la siguiente manera:

Política mediante, el proyecto educativo de la República Conservadora concurrió a la reproducción de las condiciones de producción de la patria ganadera y antiindustrialista. La inmigración excesiva e inadecuada para un país cuyos dirigentes habían decidido restringir el progreso a la estética, comenzó a resultar una molestia, cuando no un enorme peligro, a los ojos de la misma clase que los había convocado. Se asignó a la educación la misión de asfixiar los "hábitus" originales de la masa inmigrante.

Es decir, los propósitos pedagógicos estuvieron orientados desde un principio más hacia la instrucción moralizadora y, en alguna medida, a la homogenización ideológica que al fomento y desarrollo intelectual de los educandos. De allí una configuración pedagógico-didáctica fundada principalmente en las formas universalistas prescriptivas: el docente es esencialmente un difusor de la cultura que la clase dominante consideraba socialmente relevante para la socialización de la "barbarie", tanto interna como la que venía principalmente en los barcos desde la lejana Europa.

Del sujeto pedagógico según el constructo que Puigrós (1990) emplea para analizar detenidamente los orígenes del sistema educativo moderno, cobra especial importancia desnudar el discurso pedagógico normalista, bajo la tutela de su gran mentor y rector: Domingo Faustino Sarmiento. En términos de Puigross (1990), el discurso pedagógico liberal del sanjuanino se constituye en la fragua donde se forja el proyecto de formación de la docencia, tal como se la conoce hoy.

La escuela normal, primera institución del estado que asume la formación profesional de educadores, se cimenta sobre los ideas sociopolíticas de Sarmiento acerca del rol de la educación en la sociedad que comenzaba a dejar sentir sobre sí los arremolinados vientos de la modernidad.

Sin embargo, los normalistas se vieron envueltos en fuertes contradicciones dadas las condiciones políticas de la época. Su concepción liberal de la educación, en cuyo proyecto pedagógico se preveía un lugar por demás protagónico para los inmigrantes europeos, chocó con la patria conservadora, representada por la clase terrateniente justamente en su proyecto oligárquico social, que considera como un nuevo elemento conflictivo en el proceso de su efectiva incorporación a la sociedad. 
Así como el indio y el gaucho en su momento representaron elementos indeseables para el ordenamiento social y la modernización del país (en esto coinciden Sarmiento y la oligarquía), ahora los nuevos visitantes de la lejana Europa se constituyen en un nuevo peligro potencial.

Si para Sarmiento el indio y el gaucho son sinónimos de la "barbarie" que apesta y corrompe cualquier proceso de desarrollo modernizador y el inmigrante es la esperanza de la instauración de una verdadera civilización a la altura de la nueva sociedad organizada, para la oligarquía terrateniente éstos últimos se ubican también en la primera clasificación asignada por Sarmiento a los indios y a los gauchos.

En este punto de la historia es donde aparece uno de los aspectos medulares del mandato liberal sarmientino pero resuelto en el marco del proyecto conservador de la oligarquía; resolución por demás atravesada por la fuerza de dichos mandatos contrapuestos. Como lo plantea Puigross (1990, p. 80):

Los normalistas lucharon entre las heredadas convicciones democráticas de Sarmiento y la pedagogía norteamericana y el placer de convertirse en los ordenadores de la cultura política nacional. Aquellos normalistas que se tornaron nomalizadores, trataron de cerrar el currículo, ritualizar, asfixiar los aspectos democráticos del discurs o sarmientino. Ellos fueron los que pasaron a la historia como los organizadores de la escuela argentina.

Para Sarmiento, la educación cobra crucial relevancia en la construcción de un país moderno a semejanza de los Estados Unidos y los países europeos más avanzados de la época, pero invirtiendo el proceso que tuvo en dichas regiones: allí la educación acompañó al proceso transformador puesto en marcha por la lógica de burguesía industrial. El sistema educativo moderno nace y se organiza como uno de los pilares donde se asientan los Estados Nacionales. Según Puigross (1990) no hubo en la lógica de las burguesías europeas y norteamericana un delineamiento previo en cuanto a poner en marcha una acción pedagógica deliberada, que inculcara a la población un nuevo corpus cultural, al revés de la concepción sarmientina.

Sarmiento suponía que en la transformación y modernización profunda de una sociedad estructurada con fuertes sedimentaciones del orden colonial hispánico, contraria a cualquier proyecto de desarrollo, la educación como estrategia política previa a la constitución del Estado Nación en su pleno desarrollo, favorecería la constitución de un nuevo sujeto social, imbuido en una percepción sustancialmente acorde al pensamiento liberal de las sociedades más avanzadas.

Los casos de Europa y los Estado Unidos demuestran lo contrario; allí la escuela moderna, se organiza sobre la base los cambios profundos que re-estructuran a dichas sociedades. Como dice Puigross (1990), la educación organizada como proyecto del nuevo Estado-Nación no es anterior a la constitución del nuevo sujeto social y del establecimiento de las nuevas relaciones políticas que mediatizan los vínculos entre los actores sociales como tampoco es causa determinante de los cambios que se suscitan en otros órdenes institucionales. Esta concepción reviste la particularidad de que los proyectos pedagógicos están instituidos en función de su arraigo a la realidad social, al revés de la visión sarmientina que concibe a esta última en función de un sistema que traza sobre la base de un ideal, los lineamientos de una nueva sociedad. 
En consecuencia, el sujeto pedagógico sarmientino es fundante del nuevo sujeto social; el mandato es que la escuela, espacio definitorio y legitimador de dicho sujeto, se constituya en una suerte de "fábrica" de ciudadanos libres e ilustrados (Martiná, 1989). Según Sarmiento, la escuela sería la encargada de transmitir marcos promotores de prácticas socializantes que reemplazaran a los viejos "hábitus" propios del orden social colonial: si los mojones sociales, étnicos y culturales de los sujetos no coincidía con los propuestos por el proyecto modernizador, debían ser eliminados. Era necesario en consecuencia, sustituir un viejo sistema de valores y creencias cimentados en tradiciones caducas, obstaculizantes a la instauración del proyecto social y político liberal del paradigma moderno. Pero en el marco contradictorio de los mandatos de la clase dominante, la oligarquía que si bien coincide parcialmente con el proyecto sarmientino, su objetivo de máxima es subordinar cualquier proyecto sociopolítico a la esfera de sus particulares intereses.

El sujeto pedagógico sarmientino, imbuido de los ideales democratizadores y progresistas del liberalismo, que imprimirían un sesgo fuertemente agrícola e industrialista a la vida económica del país; se trastoca en la perspectiva fundante de la oligarquía terrateniente, que había elegido un modelo de progreso y desarrollo que mantuviera inalterable el statu quo vigente en el ordenamiento socio-económico: el latifundio y la dependencia hacia las potencias hegemónicas europeas (Puigrós, 1990)

De las latitudes admiradas e inspiradoras del proyecto sarmientino, llegaron al país los docentes destinados a la formación de las primeras camadas de maestros argentinos, según el proyecto educativo político de la época. Las maestras norteamericanas intentaron, en sintonía con los ideales del sanjuanino, de formar a sus pares argentinas en el marco de los valores progresistas de la época pero dada la imposición del proyecto hegemónico del orden conservador ya señalado, el discurso pedagógico triunfante funda al normalismo como corriente pedagógica formadora de educadores, contraria a los ideales democratizadores, progresistas y pragmáticos de la pedagogía norteamericana. En palabras de Puigrós (1990, p. 84):

\footnotetext{
En una sociedad como la Argentina, donde el camino elegido por la clase dirigente había sido el establecimiento del Orden sobre un camino del Progreso que no alterara las reglas del latifundio y la dependencia de Inglaterra y pronto de los Estados Unidos, los elementos progresistas y democráticos del pragmatismo trasmitidos por las educadoras norteamericanas, serían aplastados por una pedagogía normalizadora.
}

Una vez aniquilados los elementos "subversivos" contrarios a la civilización del Orden y el Progreso con la culminante campaña de exterminio del indio y el sometimiento del gauchaje, las expectativas puestas en la inmigración europea pronto se ven frustradas al comprobar que el perfil cultural de los nuevos invitados dista del nivel esperado. En efecto, el grueso de los inmigrantes europeos provienen de los estratos sociales más pobres, con el consecuente capital cultural diferente al imaginado por la clase dirigente de nuestro país. Nuevamente asoma en el horizonte, la visión de un peligro en ciernes: el hecho de haber convocado a elementos indeseables para el proyecto sociopolítico que la oligarquía y sus servidores tienen en mente.

Aquí es donde se concibe a la educación en un marco de funcionalismo político claro, al conferirle la tarea de estrangular, de ahogar toda influencia de los patrones culturales de origen de esa masa de europeos que recalan en nuestras costas con la promesa de un mejor futuro. Dichos patrones, representan 
una velada amenaza al proyecto de reproducción del modelo social antes aludido: un país sustentado económicamente en el latifundio ganadero, antiindustrialista y dependiente de las potencias europeas.

¿Qué es en definitiva la pedagogía normalizadora aludida en el breve análisis histórico realizado? Es el modelo resultante, contradictorio en el que se mezclan las visiones idealistas de Sarmiento y demás intelectuales progresistas de la época, con la decisiva influencia de los agentes políticos conservadores, que bajan el precepto de los mandantes de la patria ganadera y es el que instaura las bases definitivas del sistema escolar argentino. El normalismo instituye, entonces, un paradigma donde el control social y la homogeneización cultural son los ejes prioritarios en la agenda política de la época: es la base constructiva del sujeto pedagógico, definido en la línea de tensión "civilización o barbarie"

La tradición normalizadora determina el trazado del paradigma pedagógico fundante. Dicho paradigma abreva de varias de las más importantes vertientes multidisciplinarias de la época. En la perspectiva que desarrolla Pineau (1999), se podrá apreciar cuales son los elementos constitutivos que dichas corrientes aportan y dan identidad a uno de los corpus culturales de la docencia más poderosos y que parece pervivir hasta la actualidad:

\section{a. El liberalismo \\ b. El positivismo}

El primero, le confiere a la educación su carácter eminentemente político. El sujeto, al desarrollar su experiencia educativa en un marco institucionalizado, va organizando su existencia en torno a la adquisición de su condición de ciudadano, agente social adscrito a determinados derechos y obligaciones. Esa es una de las principales razones del porqué la educación se convirtió en una razón de estado para el liberalismo: priorizada como uno de los pilares de consolidación de las naciones modernas Pero tampoco se puede de dejar de señalar que el sistema educativo, como todo movimiento institucionalizado, conlleva en su seno contradicciones: al mismo tiempo en que se constituyó en una las principales vías para el ascenso social de los inmigrantes, también legitimó, bajo el paraguas de la meritocracia, las desigualdades sociales inherentes al modelo social imperante. (Pineau, 1999)

La segunda fuente, abona al paradigma pedagógico normalizador en cuanto aportar una identidad cultural de base científica. En sintonía con los baluartes de la burguesía como clase dominante triunfadora, el positivismo representó el paradigma más cabal desde el cual se sistematiza una forma de conocer, organizar y difundir los saberes que conforman la cultura socialmente relevante, por un lado, la escuela adquiere el estatus de espacio institucional privilegiado, "natural", donde el indómito infante pasaría buena parte de su existencia sometiéndose a la noble y magna tarea de su disciplinamiento social, mediante el cual sería devuelto a la sociedad, convertido en ciudadano.

Por el otro lado, para alcanzar los objetivos que se proponía mediante la acción educadora, era necesario dotar a la misma de un método basado en las premisas que la ciencia como modo privilegiado del desarrollo cultural y social del hombre, ya había establecido. La ciencia, en la mirada positivista es la única garantía de progreso para la humanidad. No es casual que en esa época se atara fuertemente al campo 
pedagógico con las contribuciones determinantes de ciencias como la biología, la medicina y más tarde la psicología. Las ideas preponderantes de la época en dichas disciplinas, aportan los elementos decisivos para conferirle a la pedagogía fundante, su misión de disciplinadora social.

El discurso médico, sustentado en la concepciones biologicistas del comportamiento humano, fundamentalmente nutridas desde la reinterpretación sociológica de la teoría natural de Darwin (denominada darwinismo social), dio los elementos fundamentales para la construcción de un discurso pedagógico destinado a erradicar los "hábitus" e "inevitables enfermedades" de origen, primero del inmigrante europeo y luego de los propios argentinos que más tarde mudarían su condición de obreros rurales para incorporarse al proceso de industrialización en las grandes urbes; que impedían un proceso de natural adaptación al medio socializante superior de la sociedad moderna: la escuela. Lo que se pretende es el control total del sujeto, presuponiéndolo como biológicamente determinado y factible de ser sometido a un método universal que lo instara a aprender, más allá de su voluntad. (Puigrós, 1990).

No es casual que además de las funciones docentes definidas en el aula escolar, en tanto alfabetizador y disciplinador de los futuros ciudadanos, al maestro se le encomiende llevar adelante, en el marco de la comunidad de inserción de la institución, campañas de salud y acciones de asistencia social. Estas últimas muy ligadas a las problemáticas de control social. (Davini, 1995).

Así, la escuela asume la misión fundamental para el nuevo orden social, de clasificar a los sujetos según sus capacidades innatas. La construcción del nuevo sujeto social a través de la acción educadora del aparato escolar, exigía a los individuos determinadas condiciones y aptitudes que la escuela, bajo el paraguas del discurso médico hegemónico, asume la misión de evaluar y diagnosticar. Ello se encuadra una vez más, en la perspectiva de mantener una elevada eficiencia del control social de un modelo educativo que se muestra desde un principio como altamente represivo. (Puigrós, 1990).

Huelga decir, que estas ideas legitiman las históricas clasificaciones de los indivi duos según sus capacidades y características (de orden social y cultural preponderantemente), que la propedéutica educativa llevó adelante. Aún hoy se escuchan frases y expresiones como: "la inteligencia es un don natural"; "a este chico no le da"; "proviene de una familia pobre, le cuesta mucho aprender"; "la inteligencia es como una varita mágica: algunos lamentablemente no han sido tocados por ella"; "éste tiene un talento especial"; "más no se le puede pedir"; "etc." La idea de la inteligencia como una capacidad innata, una dotación puramente de origen biológico continúa siendo de gran peso en el discurso pedagógico de hoy, aunque atenuado por el disfraz de ciertas expresiones eufemísticas. Las desigualdades y diferencias sociales, culturales y hasta étnicas nunca terminaron siendo reconocidas por el sistema escolar como una de las madres fundamentales del origen de las problemáticas que minan las posibilidades del éxito del educando. En palabras de Puigrós (1990):

La recurrencia a modelos biológicos y organicistas buscaba explicar las diferencias sociales y justificar las políticas, reduciendo los procesos psico sociales a categorías universales de aquellos órdenes. La intención era que, de tal manera, las determinaciones, las consecuencias y las soluciones del problema de la desigualdad y de las luchas sociales, no afectarían teórica ni prácticamente las relaciones establecidas entre los sectores desiguales. Quedaban fuera de la política y se reducían a la "cura" psicológica o pedagógica. Para ello era recesario definir los sujetos sociales conflictivos en escalas biológicas y psicológicas y no reconocer el origen político de las desigualdades sociales. 
Bajo este paraguas se definió a la naturaleza didáctica del paradigma fundante; ésta se caracterizó fundamentalmente por concebir al conocimiento como algo acabado y cerrado; bastaba con que el mismo fuera "bajado" por el docente al alumno, quién pasivamente lo recibía. El primero debía asimilar en su formación una serie de procedimientos, homologados desde la perspectiva cientificista propugnada por el positivismo, que conforman un método universal para enseñar los conocimientos que se ponen en juego en el aula. Dicho método es el alma mater que organiza y ordena los espacios y los tiempos pedagógicos del aula escolar, en la que cobra especial relevancia el docente quién privilegia como procesos psicológicos responsables del aprendizaje, aquellos que se apoyan en la memorización mecánica y repetitiva. Al alumno se lo concibe como un ente pasivo, imbuido en un quietismo (control de los cuerpos) garante para la inculcación del conocimiento; es pensado asimismo como un recipiente vacío (de ahí el reduccionismo biologicista, del carácter asocial de los sujetos y la necesidad de formar su mente) a ser llenado con los conocimientos puestos en juego. Por supuesto que ni los intereses ni las ideas del alumno son tenidas en cuenta.

En consecuencia, el proyecto sociopolítico de la época, perfila al maestro como un agente socializador de suma importancia para la difusión de los elementos esenciales, en tanto universo simbólico a ser asimilado por un colectivo sumamente heterogéneo, que les garantizaría su efectiva incorporación como ciudadanos. El maestro, en este escenario, fue asimilado a un papel de "civilizador", a una suerte de garante del proyecto de modernización social pero fundamentalmente, sin saberlo, a facilitar la reproducción y perpetuación del proyecto impulsado por la oligarquía como clase social dominante. La sagrada vocación docente, la asimilación de éste a la del papelde los antiguos misioneros que venían de lejanas tierras a evangelizar a los indómitos salvajes, en suma, la acción redentora llevada a cabo día tras día en las aulas, se asumen como uno de los elementos centrales en la configuración de la tradición normalista. Davini (1995, p. 23), citando a Alliaud, dice:

Definido el papel del maestro como encargado de difundir un nuevo mensaje tendiente a realizar la asimilación simbólica de las nuevas clases populares y la integración moral contra las diferencias regionales o familiares, la tarea de enseñar consistía en [...] la simple difusión de saberes generales. Por lo tanto, el maestro, al igual que el sacerdote, necesitaba para llevar a cabo su función civilizadora (casi misionera), la creencia [...] en las posibilidades redentoras del nuevo mensaje (Alliaud, 1993, pág. 136)

La misión "evangelizadora" del maestro apoyada en el marco pedagógico nutrido en principio por la filosofía positivista de la época, convertida en la fuente epistemológica por excelencia, le confiere a la educación un estatus científico; derivándose la configuración de los métodos didácticos. Dichos métodos observan la premisa de su universalidad, en cuanto a ser aplicados para todos los individuos escolarizados y por los cuales, se alcanzan las metas prefijadas.

La máxima "Orden y Progreso" enarbolada como estandarte de la modernización del país, produce una impronta en el imaginario pedagógico de construcciones simbólicas universalistas, tendientes a negar y reemplazar a los valores y concepciones que no estuvieran en consonancia con el nuevo pensamiento modernizante. En consecuencia, el propósito central de la acción llevada acabo por el maestro se orientó desde un principio más hacia el disciplinamiento moral de las masas, conjugando para ello un discurso ideológico común que borrara todo rastro de la heterogeneidad propio de una sociedad que se integra a 
partir de individuos que provienen de diversos entornos socio-culturales, que a la educación centrada en la estimulación y desarrollo del conocimiento y las habilidades intelectuales. (Davini, 1995).

La diseminación de las escuelas normales por todo el país, a los efectos de formar los recursos docentes necesarios, muestran a las claras la necesidad de llevar hasta el último confín del país el mensaje civilizador de la escuela, como estrategia de base en el proyecto de construcción de la nación. Esta idea, de llevar la voz de la civilización a todo el territorio, determinó la aparición de otra impronta en el imaginario docente, reforzadora de la idea del "sagrado papel evangelizador" aludido, la del maestro sacrificado, patriota, entregado a la noble causa de la construcción de la nueva nación. La prerrogativa sarmientina de "educar al soberano", encuentra aquí su terreno fecundo. La utopía de la empresa educativa del maestro normalizador encuentra su razón de ser en esta magna tarea: llevar el progreso y la civilización hasta el último rincón de la nación. Es así que los docentes son constituidos en una trama pedagógica, en la que se apela a la "vocación de servicio", a la "misión trascendental de desterrar la barbarie", a la moral como ejemplo, etc.

Zulema Caballero (2001), apoyándose en análisis de autores como Tomaz Tadeu da Silva e lan Hunter, analiza el rol de los sistemas educativos formales de occidente, a partir de su genealogía. En dicho análisis se plantea que la escolarización masiva, en la mayoría de los países occidentales, respondió a las políticas de estado de los gobiernos, siempre en el contexto de las necesidades que ellos se plantearon para plasmar su particular proyecto político. Según la autora, el sentido de la palabra gobierno se comprende, utilizando la significación particular que le da Michel Foucault, como una configuración para la organización de los asuntos sociales de un colectivo, en aras de poder obtener el máximo rendimiento social del mismo, pensando siempre en los objetivos estatales a satisfacer.

Según Caballero (2001), Hunter concibe a la escolarización de masas como una estrategia propia de los estados -nación de la modernidad capitalista, que está íntimamente vinculada a una tecnología moral, el "pastoralismo cristiano", es decir, se echa mano de los preceptos del catecismo cristiano para codificar moralmente, el comportamiento de los sujetos, vehiculizándolo a través de la maquinaria burocrática del estado, es decir, la institución educativa en este caso. Ello implica siempre un fin último de control social. La escuela no tendría otro objetivo, en este plano de su funcionalidad formativa, mediante toda una suerte de "maquinaria moral" que la de formar sujetos dotados de capacidades de autocontrol para desenvolverse socialmente.

Otro elemento a tener en cuenta es el hecho que cobra siempre notoriedad en los estudios caracterológicos del sistema educativo argentino y es la presencia mayoritariamente femenina en el desempeño del rol docente, por lo menos en el nivel de la educación básica. Recurriendo una vez más a los análisis de Davini (1995) y Puigross (1990), la docencia se constituyó en principio como una ocupación femenina dado el valor asociado al carácter tutelar que adquiere desde un principio, en consonancia con el discurso pedagógico moralizador. En efecto, en el marco de las tradiciones imperantes, nos referimos al modelo amiliar tradicional, el maestro pasa a definirse como la "segunda madre", la escuela como "el segundo hogar". De la educación de los hijos, tal como reza el catecismo de dicho modelo, se ocupa principalmente la mujer. Estas improntas se evidencian aún hoy en el contexto escolar, divorciado y 
enfrentado socialmente a un modelo familiar contemporáneo, diferente al imperante a principios del siglo $X X$.

La resultante de esta impronta, es un proceso de socialización secundaria concebido como un modelo de transmisión de modos de comportamiento, de formas y estructuras de valorar la realidad. El "segundo hogar" no es más que una usina de inculcación de ideología, en consonancia con el proyecto de homogeneización cultural, que se caracteriza por su escasa solidez argumental pero dotada de una gran carga afectiva que le confiere eficacia en su impacto en los noveles educandos.

La tradición normalizadora, como se ve, se constituye en un modelo fuertemente atravesado por el ideario de un proyecto sociopolítico, que asigna a la educación una misión esencial: la inculcación de un arbitrario cultural que sustenta determinadas relaciones de poder entre los actores sociales. El paradigma resultante, baja una pedagogía prescriptiva, no solo determinando lo que cada educando cebe ser sino también como debe ser un verdadero maestro. En este sentido vale destacar improntas, vigentes aún hoy, como por ejemplo la imagen del buen maestro: el maestro sacrificado y entregado a sus alumnos, el maestro como guía y ejemplo moral; el maestro como portador de la luz esclarecedora del conocimiento; etc.

Estas características se asociaron con otras, configurando un modelo de formación docente que aun hoy conserva fuertes rasgos provenientes de las improntas originales. En principio la formación docente es de eminente carácter instrumental, con débil formación teórica y disciplinaria. El "saber hacer" ha sido y es uno de los ejes centrales de la formación. Es muy común escuchar a muchos docentes que mejor que la teoría (aludiendo a los cursos y seminarios de perfeccionamiento docente, más allá de sus reales valores de eficacia) se requiere práctica para dar cuenta de la problemática del aula.

Un catecismo de procedimientos y rutinas y cierto dominio en el manejo de materiales completan el modelo. Así, el maestro se ve como un mero instrumentador de saberes básicos, mayormente fragmentados y descontextualizados, con cierto dominio de limitadas técnicas didácticas para el gobierno del aula pero fundamentalmente carente de conocimientos epistemológicos sólidos de los diferentes paradigmas pedagógicos y didácticos.

La tradición normalizadora, en tanto generadora de improntas modeladoras necesarias para el disciplinamiento social, formó al maestro bajo un enfoque socializador poco permeable a las diferencias. De ahí que la escuela haya sido un espacio institucional poco proclive a la integración de la hetoregeinedad social y diversidad cultural de los educandos. Las hipótesis acerca de las aptitudes de sus alumnos, responden a estas improntas que han configurado modelos de socialización destinados a la clasificación de los individuos, según ya se explicó.

Así, esta visión negadora de la diversidad y pluralidad de valores, saberes e intereses propios de una sociedad real forjó la impronta en el maestro de una visión social irreal. En efecto, la homogeneidad social y cultural como tal no existe, por más que se intente mediante acciones sistematizadas moldear a los sujetos en una matriz. Es la misma problemática que hoy observamos en el paradigma económico dominante y su lubrificante cultural denominado pensamiento único. Al respecto vale destacar una vez más las palabras de Davini (1995, p. 27 ): 
Ello ha contribuido a fomentar la idea de una "escuela ilusoria", y se consolida una escuela cargada de símbolos abstractos, rituales y rutinas homogeneizadoras. El problema estriba en que la homogeneidad social, cultural e interindividual no existe, y al distanciarse de lo "distinto" se pierde el diálogo de la pedagogía, que supone siempre una relación entre sujetos diferentes.

La tendencia a "modelizar" la realidad y a manejarse con estereotipos (Carrizales, 1988) tiene su correlato en la concepción del docente como responsable de ser el ejemplo o modelo, impulsado a acciones de entrega personal. Ello ha dificultado que durante muchas décadas, el maestro su autopercibiera como un trabajador, definido profesionalmente dentro de un discurso de desinterés material. Coherente con el mismo y como correlato de su origen histórico en la constitución del "Estado docente", esta tradición ha marcado el disciplinamiento de maestros y profesores respecto de las normas prescriptivas emanadas del aparato estatal. Ello ha dado a la docencia mucho más la imagen de funcionarios de Estado que la de categoría profesional.

Bajo esta visión, suele circular en los discursos la nostalgia respecto de la formación del antiguo normalismo. Tal vez la frecuente expresión de nostalgia por lo "perdido" tenga que ver mucho más con la pérdida de un proyecto social y educativo compartido y asumido por la sociedad que con los propios méritos de aquella formación o con la intención de conservarla.

Las permanentes quejas de maestros y profesores acerca de la devaluación social y material que la tarea docente viene sufriendo y que ha acentuado en las dos últimas décadas, son otro botón de muestra de la persistencia de las improntas originales, en un contexto de profunda crisis cultural y social, donde el proyecto educativo de la modernidad es seriamente cuestionado: anclados en realidades que tienen más que ver con construcciones míticas, los docentes persisten en definir a la práctica educativa en el marco del optimismo pedagógico (Carusso y Dussel, 1995), fiel legado de la herencia sarmientina.

El problema grave es que el contrato social donde se inscribe dicho paradigma pedagógico se encuentra agotado, por lo que maestros y profesores tratan de buscar y encontrar refugio ante la natural impotencia de ser expulsados del paraíso, ya en el reclamo a las autoridades de "bajadas de línea adecuadas", ya en el reforzamiento intenso de definir su tarea como "un gran compromiso con sus alumnos".

La doble desvalorización que la tarea docente sufre, ya por parte de una sociedad que ora viene desmitificando los sacralizados saberes escolares, ora nutriéndose de conocimientos de otras fuentes como los medios masivos de comunicación, ora evaluando que la escuela no aporta lo mínimo indispensable para insertarse en un mundo de creciente complejización cultural, ya por parte del propio estado con políticas reformistas improvisadas, ambiguas y contradictorias, además de reforzar la pauperización salarial, crean una situación de alto riesgo para la profesión, minando las posibilidades para plantear estrategias innovadoras, destinadas a impulsar cambios profundos en la práctica educativa.

Para finalizar, veamos en el siguiente cuadro, el resumen del modelo pedagógico concomitante al paradigma normalizador en la formación docente: 
NÚCLEO CONCEPTUAL:

"Pretende la formación social de todos los individuos, a través de la acción educadora del Estado Nacional"

\section{BASE FILOSÓFICA:}

Positivismo: aplicación de bases científicas a la configuración de los métodos didácticos.

lluminismo: saberes rigurosamente clasificados en disciplinas.

BASE HISTÓRICO-SOCIAL:

Liberalismo: asignación a la escuela como agente privilegiado de la socialización. La educación como política de estado para el disciplinamiento social que exige el nuevo paradigma económico.

BASE PSICOLÓGICA:

No se plantea un marco teórico en especial pero más adelante, la perspectiva conductista (las teorías conexionistas) contribuirá a aportar el soporte psicopedagógico al modelo.

\section{MODELO DIDÁCTICO:}

Para qué enseñar: Proporcionar las informaciones fundamentales de la cultura vigente. Obsesión por los contenidos

Qué enseñar: Síntesis del saber disciplinar. Predominio de las "informaciones" de carácter conceptual.

Cómo enseñar: Metodología basada en la transmisión del profesor. Actividades centradas en la exposición del profesor, con apoyo en el libro de texto y ejercicios de repaso. El papel del alumno consiste en escuchar atentamente, "estudiar" y reproducir en los exámenes los contenidos transmitidos. El papel del profesor consiste en explicar los temas y mantener el orden en la clase.

Rel. Alumno-docente: la autoridad absoluta del docente en relación al alumno. No se tienen en cuenta ni los intereses ni las ideas de los alumnos: "la tábula rasa"

Evaluación: Centrada en "recordar" los contenidos transmitidos. Atiende, sobre todo al producto. Realizada mediante exámenes.

\section{El paradigma tecnológico}

Pasemos ahora a analizar otro paradigma de gran impacto en la formación docente y en los cambios sustantivos que introdujo en la configuración institucional de las prácticas educativas; así se hace necesario posicionarse en el contexto histórico que lo dio a luz: la década de1960, en plena "revolución desarrollista".

Imbuidas en el atraso crónico, las sociedades como la de Argentina, abrazan con fervor una fórmula, de horizontes prometeicos, para alcanzar el grado de desarrollo de los países centrales. Es así, que la condición de subdesarrollo podía ser superada, y avanzar en consecuencia hacia la posición que ostentaban las naciones industrializadas, introduciendo profundas reformas en el marco de la escolarización formal. La fórmula, por supuesto, la van a brindar las naciones "top" del mundo industrial, quienes guiarían a los países atrasados hacia la ventura del desarrollo.

De esta manera, se reubica a la escuela al servicio del despegue económico, enganchando a la educación en forma directa con la esfera de la economía; es decir, se la concibe como inversión, como formadora e recursos humanos para la demanda laboral de los nuevos puestos de trabajo que demanden, a consecuencia de la modernización económica, el sector industrial o en el sector comercial. (Davini, 1995).

La tesis de cambio que sustenta la médula del paradigma desarrollista es que las naciones subdesarrolladas mantienen configuraciones sociales y culturales fuertemente atadas a tradiciones contrarias al modelo progresista del mundo moderno. La innovación tecnológica es el pilar esencial para la modernización de la sociedades atrasadas, por ello el progresismo técnico es condición sine quanon para 
que cualquier nación subdesarrollada salir de dicha condición. Así, se contrapone lo "tradicional" frente a lo "moderno", lo esencial es justamente pasar desde uno hacia otro si quiere alcanzar un nivel de pleno desarrollo social como es el que gozan los países centrales. En este tránsito, a la educación se le asigna el rol de apoyo para difundir las nuevas ideas del progreso (Davini, 1995).

La escuela, bajo el gobierno del paradigma pedagógico tradicional y especialmente en el tema que se está tratando, la formación docente, bajo el paraguas normalizador es evaluada como atrasada para cumplir con los "nuevos mandatos asignados desde el Olimpo por los dioses de la modernidad". De lo que trata es de extrapolar el modelo de organización industrial, de incuestionable éxito en la productividad de las empresas, al mundo institucional de la escuela, en un intento de darle una configuración análoga en pos del objetivo de máxima que pretenden los mentores desarrollistas: la eficiencia.

La actual organización institucional de la escuela y de los diferentes estratos del sistema educativo son en gran medida, producto de este modelo, sustentado en preceptos eminentemente técnicos. La división de roles netamente diferenciados por jerarquías técnicas, bajo el paraguas de una racionalidad de cuño taylorista, persiguió la meta de economizar tiempos y esfuerzos para dotar a las prácticas educativas de la máxima eficacia, según objetivos previa y rigurosamente planificados. La tarea docente, por primera vez pierde un importante margen de autonomía, ya que la planificación de la enseñanza pasa a estar a cargo exclusivamente de otros técnicos, los planificadores; a ellos solo le cabe la "magna" tarea de "bajar" los contenidos al aula, en torno a objetivos previamente planificados y la consecuente medición, por cierto que rigurosa, de los resultados de los aprendizajes. En palabras de Davini (1995, p.37):

Con ello, se introdujo la "división técnica del trabajo escolar", separando a los planificadores, los evaluadores, los supervisores, los orientadores educacionales y muchas otras categorías, y la función del docente quedó relegada a la de ejecutor de la enseñanza. Por primera vez aparece la organización del currículum como proyecto educativo elaborado por "otros", esto es, constituyéndose en un objeto de control social

En el plano específicamente didáctico, surge el modelo tecnológico que pasa a reemplazar al modelo tradicional. El sustento desde el punto de vista psicológico, lo proporciona la moderna teoría conductista, fundamentalmente a partir de los aportes de B. F. Skinner. Así, en el esquema del modelo de la caja negra, el aprendizaje es concebido en términos de "entradas" y "salidas", lo que facilita elaborar dispositivos didácticos rigurosamente planificados. En éste sentido la preocupación gira en torno, no sólo a la enseñanza de los contenidos (debidamente aggiornados a realidad científica) que han sido elaborados por los expertos y puestos a disposición de los docentes ya entrenados para la tarea de "bajarlos"; sino que cobra una particular relevancia pedagógica las habilidades y capacidades formales que facilitan, al alumno una mayor capacidad de adaptación, ergo, aprendizaje.

Ahora bien, pasando concretamente al tema de la formación docente, el paradigma tecnológico fue el que propició la salida de la formación de los maestros del nivel secundario y la reubicó como carrera de nivel terciario; así, las históricas escuelas normales dejaron de alguna manera de existir y se constituyeron los institutos de formación docente y en algunos casos, la universidad también comenzó a ocuparse de ésta tarea. Asimismo, la formación profesional de los docentes de los otros niveles de la enseñanza, pasó a la órbita del nivel terciario. La lógica que animó a dicha política de formación se enmarca en los términos 
definidos por la máxima de este paradigma, es decir, el "eficientismo profesional del docente". Los conocidos elementos que aun hoy tienen vigencia en buena parte de las prácticas docentes como ser la importancia de la planificación como uno de los requisitos fundamentales para desempeñar una verdadera labor profesional en la enseñanza, la evaluación centrada en el rendimiento académico, la utilización de recursos tecnológicos en el aula como forma de modernización didáctica, la proliferación de técnicas de dinámicas grupales como recurso renovador y por ende transformador de las prácticas docentes, aportaron los ladrillos para la construcción del nuevo edificio pedagógico.

Como ha sucedido en la mayoría de los movimientos renovadores de la educación, el paradigma tecnológico irrumpió en el campo educativo imbuido en el espíritu del más puro optimismo pedagógico: había llegado la hora de poner a la escuela a la altura de las circunstancias sociales, llevándola directamente a ponerse al servicio de las demandas modernizadoras del mundo económico. Tal como ocurre con la actual reforma educativa, el paradigma tecnológico se impuso ante los diversos actores del sistema educativo como el salvador de todos los problemas que mantenían a la educación en un estado de anquilosamiento, dado los claros síntomas de agotamiento del paradigma normalizador. Simple, lineal y efectista, el discurso modernizante y eficientista de este modelo pronto se apoderó de la palabra de la docencia.

A nivel de las improntas que este modelo introdujo y cimentó por un lado y por el otro reforzó representaciones ya existentes, es de destacar por ejemplo, la visión instrumental de la enseñanza, ya que es una de las huellas más fuertes acuñadas en el imaginario pedagógico y que persiste hasta nuestros días; es más, se ha visto revalorizada en el marco actual de la reforma: el mito de la previsibilidad del producto final a obtener, a partir de la rigurosa planificación de las prácticas educativas; la lógica disciplinar como instrumento de adquisición de conocimientos, el mito de la lógica de los "inputs" y "outputs" como eje medular de las prácticas de la enseñanza; la división rigurosa del campo educacional entre dimensión administrativa y dimensión pedagógica; el mito de las aptitudes naturales de los educandos, llevados al extremo de su comparación con estándares de pretendida rigurosidad científica.

Cada uno de estos mitos o improntas calaron profundamente en el imbricado entretejido institucional del sistema educativo. Esto facilitó el ahondamiento de la fragmentación discursiva de la docencia, empujando a las prácticas concretas cada más hacia una visión simplificada del hecho educativo. Los productos que estos mitos han dejado como legado y que llegan hasta el día de hoy con renovadas energías desde la discursiva oficial, vale destacar la preeminencia de conceptos como racionalización, eficiencia profesional del docente, calidad del producto, planificación, el docente como técnico, la capacitación docente orientada a cuestiones netamente de aggiornamiento técnico, etc.

El otro de los legados esta relacionado con la irrupción definitiva de la psicología en el ámbito escolar. Si bien la historia de los equipos de orientación escolar se remontaba a principios de los años '50, es de la mano de esta tradición donde van encontrar una fuerte legitimación, produciéndose la expansión a numerosos ámbitos institucionales, principalmente en la enseñanza primaria. Si el mito de las aptitudes naturales adquiere el rango de variable determinante para evaluar los desvíos con relación a los estándares, los gabinetes psicopedagógicos, munidos de la artillería provista por la psicometría, encuentran su razón de 
ser en la evaluación y medición de las disfuncionalidades detectadas por los docentes en los educandos. Por supuesto que esto es en términos generales, que siempre hubo personas abocadas a poder desentrañar la trama que se ocultaba detrás cada "fracaso escolar", evitando en la medida de sus posibilidades, victimizar al educando por su supuesta falta de aptitudes.

Una de las principales consecuencias de lo anteriormente expuesto, es el escamoteo velado de la naturaleza real de la práctica educativa como fenómeno social, atravesado fuertemente por aspectos ideológicos, velados en gran medida, y que le confieren una naturaleza eminente política, en tanto ser docente es tomar decisiones y asumir las responsabilidades consecuentes. En efecto, al separar al docente de su práctica, en tanto su misión debe ser solamente "bajar" los contenidos preescritos por los expertos en el currículum oficial, se lo despoja a éste por un lado, del control efectivo de la enseñanza, se cercena su autonomía profesional y por el otro, se lo imposibilita en tanto pueda re-pensar los fundamentos de su propia práctica. Es decir, en tanto y cuando se vea a sí mismo como un agente social atravesado por factores culturales, políticos ideológicos que condicionan su accionar en el espacio institucional, visualizando a éste en el mismo nivel de complejidad aludido.

En el marco de la capacitación docente, se delineó una política que se ha ampliado, consolidado y legitimado en el panorama actual de la reforma: los "expertos" elaboran el material, configurados como paquetes que se bajan a los ámbitos de formación y perfeccionamiento, a los que los docentes les cabe el trabajo de asimilar y poner en práctica. Como correlato a esta modalidad, se inicia una fructífera industria editorial que inunda el campo educativo con textos elaborados bajo consignas eminentemente prescriptivas de la enseñanza. Hoy por hoy, esta concepción se ve fuertemente ampliada con la profusión de materiales bibliográficos, muchos aportados como material de lectura recomendada por los organismos oficiales.

Si la tradición normalizadora, con todo lo que se le puede achacar en tanto discurso pedagógico destinado a la homogeneización cultural de las masas, revalorizaba la tarea docente invistiéndola de una carga simbólica de prestigio social (recordar "la sagrada misión del maestro patriotero, llevando el conocimiento hasta el último confín del país, empujando las sombras de la ignorancia y la barbarie"), con la tradición que impuso el paradigma tecnológico, el maestro se ve crecientemente despojado de tal investidura, reubicándolo en un mero ejecutor de prescripciones elaboradas por los saberes de los expertos. Davini (1995, pp. 39-40) es lo suficientemente elocuente cuando cita las palabras de un funcionario de la Subsecretaría de Educación de la Nación, con fecha de 20-02-78:

Los maestros y profesores no intervendrán en la formulación de los objetivos, caracterizaciones y nóminas de contenidos. Es necesario aceptar de una vez por todas que la función docente consiste en educar y que su titular no debe ser sustraído de esta labor con intervenciones que finalmente carecen de mayor efecto [...] Esta tarea estará a cargo de personal jerárquico de las sedes centrales de los organismos.

Para cerrar el análisis de este paradigma, veamos en el siguiente cuadro, el resumen descriptivo del modelo pedagógico concomitante:

\section{TESIS:}

"La tecnología de la instrucción, permite la transferencia de información básica para que la acción educativa tenga lugar" 


\section{BASE HISTÓRICO-SOCIAL:}

Contexto del progresismo norteamericano, que pone el acento optimista del mejoramiento del hombre, a partir del moldeamiento del comportamiento mediante métodos. científicos.

\section{BASE PSICOLÓGICA:}

Se apoya básicamente en los aportes del paradigma conductista, cuyo eje central está puesto en la acción del medio ambiente como determinante de la conducta

MODELO DIDÁCTICO:

Para qué enseñar: Proporcionar una formación "moderna" y "eficaz". Obsesión por los objetivos. Se sigue una programación detallada.

Qué enseñar: Saberes disciplinares actualizados, con incorporación de algunos conocimientos no disciplinares. Contenidos preparados por expertos para ser utilizados por los profesores.

Cómo enseñar: Metodología vinculada a los métodos de las disciplinas. Actividades que combinan la exposición y las prácticas, frecuentemente en forma de secuencia de descubrimiento dirigido.

Rel. Alumno-docente: El papel del alumno consiste en la realización sistemática de las actividades programadas. El papel del profesor consiste en la exposición y en la dirección de las actividades de clase, además del mantenimiento del orden. No se tienen en cuenta los intereses de los alumnos. Sus ideas previas, son consideradas como "errores" que hay que sustituir por los conocimientos adecuados.

Evaluación: Centrada en la medición detallada de los aprendizajes: imp. Producto.

\section{El paradigma academicista}

Si bien el paradigma normalizador constituye el modelo fundante en la formación de recursos docentes para las instituciones escolares que imparten educación masiva y obligatoria; en los otros niveles del sistema educativo, como la universidad y la escuela media se perfiló otro modelo de formación, cuyas características difieren del paradigma normalizador.

En primer lugar es necesario destacar que la educación media respondió a imperativos sociopolíticos muy diferentes a los otorgados a la educación primaria. Si ésta estaba destinada a la alfabetización instrumental y moral de las mayorías, la escuela media nace como una instancia preparatoria para el acceso a la universidad de los sujetos que tenían posibilidades de acceder a cargos dirigentes. En este interín, la oligarquía porteña de fines del siglo XIX comprendió la necesidad de organizar un ámbito educativo para la formación de un estrato de intelectuales y profesionales, al servicio de la administración de sus intereses. El proyecto de país agrícola-ganadero y antiindustrial, necesitaba de una pléyade de dirigentes formados a tales fines.

La educación media en nuestro país fue impulsada bajo la gestión de Bartolomé Mitre. La matriz original del modelo pedagógico sustentador de la misma, se nutrió de un mosaico combinado de concepciones provenientes fundamentalmente del pensamiento liberal europeo. La condición de nación dependiente del capital británico, voz cantante del régimen capitalista mundial, requirió de una educación formadora de sujetos pedagógicos de mentalidad subordinada a los intereses de extranjeros; por ello se imprimió una serie de lineamientos que configuró una currícula caracterizada por el cultivo de contenidos alejados del mundo real: la enseñanza se centró en el desarrollo de temas vinculados con la cultura clásica, propias de élites ilustradas europeas, alejada de las vicisitudes del mundo económico, social y laboral.

La nutriente de base fueron los contenidos brindados por la cultura francesa, ligados históricamente al iluminismo enciclopedista. Muy lejos quedaron los proyectos educativos basados en las currícula de los 
sistemas educativos anglosajones, sustentados en una enseñanza de contenidos vinculados con el modelo utilitarista, ligados a las necesidades sociales reales.

Aquí aparece el primer indicio claro de la clásica dicotomía entre los saberes escolares y la realidad social. En mentado enciclopedismo como mal endémico señalado hasta el cansancio por pedagogos, docentes, alumnos y buena parte de la ciudadanía, tiene su raíz en ésta época. La formación de una clase dirigente adicta a los intereses expansionistas del imperio británico, requiere, entre otras cosas, de una escuela que impartiera una formación sustentada en contenidos claramente ajenos al país real pero al mismo tiempo ligado a un universo simbólico que aportara los elementos necesarios para lubricar la maquinaria ideológica. El proyecto de configurar una burguesía nacional, bajo los preceptos de intelectuales como Alberdi, son abortados bajo este modelo. Como lo plantea Puigrós (1990, p. 93):

En la mentalidad de los administradores de los bienes coloniales, estancias de la oligarquía y de reacciones comerciales con el capitalismo avanzado, estaba ausente el viejo utilitarismo que inspiró la memoria de Manuel Belgrano y el modelo de construcción propuesto por Alberdi. Aquella ausencia se tradujo en currícula enciclopédicos, afrancesados y desconectados del mundo de la producción y del trabajo.

En síntesis, si la tradición normalizadora de la formación docente centro sus esfuerzos a formar recursos cuya acción educativa estaba destinada a la homogeneización pedagógica de las masas, la tradición academicista respondió a la necesidad de formar recursos docentes destinados a la educación de sujetos que provenían de estratos socioeconómicos diferentes, con intereses diferentes, centrados en la prosecución de estudios superiores en diferentes áreas profesionales (Terigi y Dicker, 1997).

En segundo lugar, siguiendo el análisis de Davini, la educación media respondió a un paradigma de enseñanza propio del vigente en la universidad. En efecto, los docentes que ejercieron en principio en las aulas de los primeros colegios (en particular, en el emblemático Colegio Nacional de Buenos Aires), provenían de la universidad. La dominante en el pensamiento docente de la universidad lo constituye una visión netamente positivista del conocimiento, en cuanto las ciencias de la naturaleza, de carácter eminentemente experimental, son el modelo a seguir. La sustantividad pedagógica de la enseñanza queda reducida simplemente a que los docentes dominen sólidamente la disciplina que enseñan.

Los aportes de las ciencias de la educación, en especial los conceptos que proveen los marcos y tendencias pedagógicas y la instrumentalidad de la tecnología didáctica son considerados como poco importantes, dada la evaluación que se hace de ellas como poco serias, escasas del verdadero rigor científico del que gozan las ciencias experimentales. Asimismo comparte similitudes con el paradigma tecnológico, en el sentido de la rigurosa eficiencia que se persigue en tanto reducen al aprendizaje como un producto a obtener, mediante la aplicación sistemática de una metodología didáctica sustentada en criterios científicos.

En así como éste paradigma concibe al alumno como un eminente procesador de información, por lo cual el docente considera que su objetivo es brindarle toda la información contenido en la currícula. Desde la perspectiva epistemológica, el conocimiento es provisto a partir de la condición de un docente experto en un área o disciplina determinada y que es reproducido por el alumno sin cambios; así el primero se encarga 
de hacerle llegar al segundo toda la información disponible y evaluada como relevante de la disciplina en cuestión, mediante diferentes recursos a que recurre el docente para que ello sea posible (Zaccagnini, 2000).

En síntesis, es claro que el perfil epistemológico del modelo positivista es la nutriente de base de este paradigma de la enseñanza, sustantivizando la lógica, el carácter sistemático y objetivo de la metodología propia de las disciplinas específicas, como el reaseguro para que el alumno, reproduciendo los saberes de las mismas, logre efectivizar el aprendizaje. Zaccagnini (2000, p. 19), citando a Teresa Mauri (1993, pp. 69-70):

\footnotetext{
"Esta decisión sobre el contenido escolar se tomó, desde nuestro punto de vista, fundamentalmente, en las siguientes dos convicciones:

a) Sí, como hemos señalado, el aprendizaje consiste en reproducir el conocimiento o la información presentada, el resultado de aprender las disciplinas formales debe ser una mente que se rige por criterios de lógica, objetividad, coherencia interna y método.

b) Si las disciplinas específicas son conocimientos organizados culturalmente, que, como su nombre lo indica, presentan el saber en formas susceptibles de ser enseñadas, entonces puede aprenderse fácilmente sin necesidad de grandes cambios.
}

En concreto, como lo señala Davini (1995), la tradición académica se sustenta bajo dos premisas fundamentales para la enseñanza: por un lado, los docentes deben poseer una sólida formación disciplinar de la materia que enseñan y de otro lado, la denominada formación pedagógica pasa a un segundo plano, ya que la misma no es considerada verdaderamente necesaria, basta con saber la materia que se dicta. El rechazo, a veces generalizado, que se observa hoy por hoy en muchos profesores cuando asisten a los cursos de perfeccionamiento docente, hacia todo conocimiento aportado por el campo pedagógico, más allá de lo discutible en cuanto su calidad formativa específica, es una prueba palmaria de la vigencia de esta impronta. Quizás, conjuntamente con el desdén con que los expertos en las disciplinas y los devaneos, a veces desesperados, de los pedagogos por convencer e imponer la imperiosidad del conocimiento pedagógico, no es más, como dice Davini (1995), de una lucha entre las corporaciones por ganar el control de la enseñanza.

En otro orden, es particularmente interesante señalar que si bien los primeros docentes que nutrieron de los recursos a la naciente escuela media provenían de la universidad, ya entrado el siglo XX se instituye la formación de profesores para el nivel medio, bajo una currícula basada en las mismas bases epistemológicas positivistas ya señaladas lo que diferencia a los profesores provenientes de la universidad, cuyo valor esencial está puesto en el dominio del saber disciplinar por sobre todo, en que aquellos enarbolan como valor fundamental la profesionalización de la labor del docente que se desempeñan en las instituciones de nivel medio.

Las diferencias entre ambos en este punto son irreconciliables, dado que se enfrentan las visiones de sujetos que provienen de estratos sociales diferentes; se evidencia las luchas de poder entre dos universos culturales con visiones e intereses por momentos contrapuestos. Esto es importante destacarlo pues aporta una evidencia más sobre lo compleja y confusa que ha sido y sigue siendo, la problemática de la tradición academicista como marco sustanciador de la enseñanza media. 
El concepto de academicismo es la nominación fuerte del paradigma que alude a saberes sólidamente organizados, estructurados y secuenciados bajo el paraguas de la lógica formal de las ciencias llamadas duras. El fuerte sesgo positivista, como ya se señaló, dotó de improntas a fuego como la desvalorización del papel del conocimiento pedagógico en la enseñanza y de la creencia de la neutralidad de la ciencia (Davini, 1995). Esto último reviste otra prueba contundente de los lubrificantes que engrasaronla maquinaria ideológica con vistas al encorsetamiento de la enseñanza a los fines políticos del control social. La pedagogía, por lo menos en nuestro país, al calor de la inestabilidad del sistema republicano de gobierno a lo largo de cincuenta años, se sometió a la racionalidad positivista mencionada, viviendo una permanente asepsia política en cuanto a sus propósitos, dando como resultado un marco fragmentario de cuerpos teóricos de escasa solidez epistemológica. Se evidencia una vez más, la desconexión del mundo educativo de la esfera del universo social, en tanto la pedagogía se ve despojada de su carácter eminentemente político como espacio de lucha entre intereses de distintos actores.

Nuevamente nos encontramos con la prueba cabal de que las reformas educativas se instrumentan a partir de la idea de que los problemas que se quieren superar, están ligados a cuestiones inherentes a la tecnología didáctica, es decir, a la instrumentación de nuevas metodologías que mejoren la perfomance del alumno en el aula. Se soslaya el hecho de que la práctica educativa concreta va mucho más allá de su instrumentalidad didáctica, incorporando las interpelaciones que mutua e interdependientemente el docente, el currículum prescripto, el alumno, el marco institucional y el contexto social y cultural que las vinculan entre sí. La actual reforma, imbuida de un supuesto marco epistemológico de corte constructivista, reduce una problemática harto compleja a cuestiones simplificadas de la enseñanza. Como lo plantea Zaccagnini (2000, p. 6) citando a Gimeno Sacristán (1996, pp. 6-7):

\begin{abstract}
"Una de las consecuencias nefastas que ha tenido esta retórica fue la de poner a los profesores frente a un discurso ininteligible. Aparte de que fuera discutible, ya que con el constructivismo no se puede hacer ninguna reforma educativa, aunque se pueden tener ideas para cambiar algunas pequeñas cosas de prácticas de aula. Ninguna teoría psicológica es capaz de dar cuenta de cómo funciona el sistema educativo."
\end{abstract}

Mas adelante agrega:

"Hoy los profesores están hartos de constructivismo curricular, de Proyectos de Centro y de diseño Curricular de Base, porqué éstas no son las formas en que a los profesores se los ayuda a cambiar sus prácticas. Para cambiar la altura de la escuela hace falta mucho tiempo, pues se trata de procesos culturales."

Hoy, en el tardío despertar de la escuela frente a los avatares que le depara la sociedad global, se vive una suerte de renacimiento de la perspectiva academicista en tanto se insiste en volver a introducir los contenidos en la escuela, luego de años de políticas desatinadas que no pocas veces la vaciaron. conocimiento escolar debería ponerse a la altura de los más recientes avances del mundo científico y tecnológico. El discurso resultante responde a la lógica señalada en la cita de Gimeno Sacristán, en tanto se reducen los problemas de la práctica educativa a cuestiones meramente instrumentales, dejando fuera del debate aspectos relacionados con el rol del aparato burocrático que sigue dominando la dinámica de la organización institucional de la escuelas; o las condiciones laborales de los docentes; o la tensión epistemológica entre los expertos productores de los saberes considerados social y culturalmente relevantes para la currícula escolar, los docentes (portadores de un saber propio, que responde a una 
epistemología particular) que deben procesarlos didácticamente para su reproducción en el ámbito áulico y los saberes previos de los propios educandos (que responden a su propia epistemología).

En suma, si bien nadie niega la necesidad la de que el docente domine aquellos conocimientos que debe enseñar, la tradición academicista deja fuera de toda discusión cuestiones fundamentales a la hora de evaluar las condiciones de la enseñanza, a partir de la formación inicial de los docentes. Las improntas mas claras, devienen en representaciones sociales de la enseñanza centradas en el modelo epistemológico del paradigma positivista de la ciencia: aprehender la lógica de la disciplina en cuestión garantiza el aprendizaje de los conocimientos puestos en juego en el espacio áulico. El saber pedagógico necesario para ello proviene del propio modelo de la ciencia: basta que el docente "baje" al alumno el conocimiento del método para asegurarse que éste lo incorpore. Bajo una organización rigurosamente estructurada jerarquizada y secuenciada de los contenidos: al aprendizaje, como modelo procesual, se lo concibe análogamente a la lógica de la disciplina en cuestión. En palabras de Zaccagnini (2000, p. 20):

La pasividad, la ahistoricidad, el reproduccionismo mecanicista, el determinismo ambiental con sus contingencias conductuales, la supremacía racionalista y su correlato de las verdades cuasi-absolutas de la lógica de la ciencia, son algunos elementos que subyacen en una y en otra concepción, por supuesto muy diferentes entre sí en referencia al como del aprendizaje, pero que ambas reducen al sujeto aprendiente a un mero papel de asimilador acrítico de los contenidos escolares. paradigma:

En el siguiente cuadro podemos apreciar la síntesis del marco pedagógico-didáctico de este

\section{TESIS:}

"El aprendizaje consiste en reproducir el conocimiento o la información presentada, el resultado de aprender las disciplinas formales debe ser una mente que se rige por criterios de lógica, objetividad, coherencia interna y método"

\section{BASE EPISTEMÓLOGICA:}

El conocimiento, provisto a partir de la condición del docente como experto en un área o disciplina determinada, es reproducido por el alumno sin cambios, le llega a él como información vía los diferentes recursos a que recurre el docente para que ello sea posible

\section{BASE HISTÓRICO-SOCIAL:}

La escuela media nace como una instancia preparatoria para el acceso a la universidad de los sujetos que tenían posibilidades de acceder a cargos dirigentes. La oligarquía porteña de fines del siglo XIX comprendió la necesidad de organizar un ámbito educativo para la formación de un estrato de intelectuales y profesionales, al servicio de la administración de sus intereses. El proyecto de país agrícola-ganadero y antiindustrial, necesitaba de una pléyade de dirigentes formados a tales fines.

\section{BASE PSICOLÓGICA:}

Se apoya básicamente en los aportes del paradigma conductista, aunque más tarde, con el ocaso irreversible de aquel, se actualizó con la irrupción del cognitivismo, en la línea del paradigma del procesamiento de la información.

\section{MODELO DIDÁCTICO:}

Para qué enseñar: Formar a los alumnos en los saberes de una disciplina determinada, centrando su enseñanza en que aquellos reproduzcan la lógica epistemológica y metodológica de la misma.

Qué enseñar: Saberes disciplinares rigurosamente organizados según la lógica científica de la disciplina; el docente debe ser un experto con sólida formación y dominio de los mismos. Los contenidos aportan al alumno no solo los conceptos (información) que necesita saber, sino el marco metodológico que dichas disciplinas utilizan para la producción y validación de sus saberes específicos. Incorporando dicho marco, es como se promueve la formación de mentes lógicas y racionales.

Cómo enseñar: Metodología vinculada a los métodos de las disciplinas. Actividades que combinan la exposición y las prácticas, frecuentemente en forma de secuencia de descubrimiento dirigido.

Rel. Alumno-docente: El papel del alumno consiste en la realización sistemática de las actividades rigurosamente planificadas. El papel del profesor consiste en la exposición y en la dirección de las 
actividades de clase, además del mantenimiento del orden. No se tienen en cuenta los intereses de los alumnos. El papel del alumno es eminentemente pasivo.

Evaluación: Centrada en la medición detallada de los aprendizajes: imp. Producto. En este paradigma es donde cobra significación el concepto "rendimiento académico"

\section{Paradigmas alternativos}

En este aprtado cabría tener en cuenta, por su relevancia, desde el activismo de la Escuela Nueva en las postrimerías del siglo XIX y primeras décadas del XX, forjado al calor de las ideas de pensadores como John Dewey, Lombardo Rádice, Giovanni Gentile, entre los más influyentes en nuestro medio con sus propuestas alternativas a la pedagogía tradicional, hasta las corrientes entroncadas con las derivaciones de los aportes piagetianos a la educación como es el caso de la pedagogía operatoria (uno de los embriones del moderno constructivismo); la pedagogía de la liberación, encarnada en los ideales de Paulo Freire; la pedagogía autogestionaria, como una de las derivaciones del movimiento rupturista del mayo francés, encarnada en figuras como Michel Lobrot; el modelo denominado de investigación-acción; la teoría crítica de la enseñanza; el modelo histórico-cultural, encarnado en los aportes de Lev Vygotsky y que hoy es uno de los aportantes al difuso y controvertido modelo constructivista de la educación; el enfoque de la pedagogía no directiva, sustentada en los aportes del psicólogo Carl Rogers, entre otros.

Por su importancia, si bien nunca terminó consolidándose y abriendo un campo de hegemonía como los tres paradigmas precedentes, analizaremos al movimiento de la Escuela Nueva (o escolanovismo) por la gravitación que tuvo en nuestro medio, en particular, por la experiencia de la escuela de las hermanas Cosettini en la Provincia de Santa Fé en las décadas del ' 40 y del '50. Los otros paradigmas nombrados, nunca se constituyeron siquiera en experiencias de la magnitud que tuvo la escuela nueva; por lo tanto no se los aboradará.

Sin duda que todos estos movimientos han tenido su relativo peso en distintos ámbitos del quehacer docente, algunos más que otros pero en definitiva, sirven para mostrar las resistencias frente a los intentos de imponer y legitimar la máxima de "pensamiento único" en el mundo de la ideas pedagógicas. Con diferencias conceptuales y metodológicas, en tanto donde se pone el acento para comprender y definir a la práctica educativa, a todas las corrientes mencionadas las unió una causa en común frente a los paradigmas hegemónicos ya analizados: el fuerte cuestionamiento al reduccionismo racionalista y cientificista de la práctica educativa. De todas formas, como se señaló, ninguna de estas corrientes llegó a gravitar como paradigma institucionalizado en el campo de las prácticas educativas, salvo en experiencias educativas aisladas, en su abordaje en el ámbito académico y de investigación de las universidades o en el desarrollo de algunos programas experimentales de formación docente.

En este orden, vale recordar que la instauración de la educación pública, masiva y laica bajo la hegemonía del paradigma normalizador, no careció de resistencias, en efecto, las luchas políticas e ideológicas en los álgidos momentos de la constitución del Estado Nacional, signaron momentos de verdadera tensión en el seno del aparato educativo. En éste sentido, el marco del normalismo progresista que Sarmiento intento poner en práctica (con los errores del enfoque ya señalados), se vio desvirtuado por éstas luchas, donde el proyecto liberal-conservador de la época lo asimiló y amalgamó en base a los 
principios positivistas ya explicitados con un nacionalismo abrevado de valores derivados de los principios católicos, sustentando y lubricando la máxima de los constructores de la organización nacional: "civilización o barbarie". Entre las tendencias que le disputaron el espacio de poder al paradigma normalizador, vale mencionar la tendencia democrático radicalizada que se diferenció del normalismo en cuanto a tenaz oposición al corte autoritario que caracterizaron las prácticas educativas impulsadas por éste último, a instituir un modelo educativo que respetara las diferencias culturales, teniendo en cuanta la cohesión ideológica a que éstos se ven sometidos, a democratizar la relación docente-alumno; en fin, pretendieron transformar las prácticas pedagógicas verticalistas en una relación pedagógica más torizontal (Puigrós, 1990).

Por supuesto que los adscriptos a este movimiento coincidían en varios puntos con los normalistas, entre ellos el precepto de la educación en manos del estado, la educación como proceso moralizador del pueblo, pero se diferencian netamente por el hecho de propugnar la democratización de las relaciones pedagógicas, con lo que chocan frontalmente con lo medular del paradigma normalizador: el autoritarismo, que es el medio más eficaz para el control ideológico y por ende social, de las masas. Más allá de algunas experiencias puntuales, como ser las desarrollada por algunos funcionarios progresistas de la época (por ejemplo, Carlos Vergara), este movimiento, nunca llegó a constituirse en paradigma con la fuerza suficiente para disputar la hegemonía del normalismo; éste, al estar legitimado desde las mismas bases del poder político, consiguió neutralizarlo en sus intentos de ampliarse y consolidarse.

Por otra parte, en este devenir donde el normalismo termina consolidándose en las primeras décadas del siglo XX, cobró singular notoriedad una experiencia educativa, desarrollada en la esfera de la educación pública e inspirada en el paradigma de la Escuela Activa o Nueva: la escuela Cosettini. Esta experiencia, desarrollada por la maestra Olga Cosettini con la estrecha colaboración de su hermana Leticia en una escuela estatal del Barrio Alberdi (Rosario), cobró singular notoriedad en una época donde el modelo pedagógico tradicional impuesto por el normalismo dominaba hegemónicamente en as aulas. Inspirada en la lectura de las ideas de Gentile y Rádice y en las experiencias pedagógicas de las hermanas Agazzi, siendo ambos a su vez inspirados por las derivaciones educativas de la corriente filosófica neohegeliana y a lo que se agrega el aporte del pragmatismo pedagógico de John Dewey; Olga Cossetini lleva a cabo la única experiencia escolanovista de real gravitación en el ámbito institucional escolar del país y se remarca este carácter de única, dado que a lo largo de las últimas dos décadas se ha constituido en un referente ineludible para el estudio crítico del campo pedagógico actual. Cuatro ideas fuerza sustentan esta experiencia, siendo dos de ellas el sello de distinción de todas las variantes del paradigma de la Escuela Nueva:

1. El alumno como protagonista central del proceso pedagógico.

2. El recate de las posibilidades educativas en el hacer

3. La integración del ámbito institucional de la escuela con el contexto natural y social donde ésta se halla inserta.

4. La concepción de que la sensibilidad y la capacidad artística y científica son aspectos diferentes pero integrados de la expresión del niño. 
El activismo y el paidocentrismo, más una visión ecológica de la educación en tanto proceso integrador de las diferentes instancias que hacen al pleno desarrollo y expresión de la condición humana, se constituyen en las bases que sustenta esta experiencia, única en el país repetimos, por su trascendencia pedagógica. En síntesis, la experiencia de Olga Cosettini se enmarca en el énfasis de la importancia que tiene el educando en tanto que asuma un papel activo en el proceso pedagógico, consciente de lo que desea aprender; en consonancia con sus reales posibilidades e intereses. Esto redunda en un cambio importante con respecto a las funciones docentes en el desarrollo de la práctica educativa: garantizar el propósito ineludible de una mayor participación y compromiso del individuo, en su calidad de ciudadano con el contexto social en el que se halla inserto; de ésta manera al satisfacer los deseos e intereses en su doble condición de individuo y sujeto social, facilitará el logro de cierto tipo de equilibrio social. En palabras de Alfonso Sánchez y González Pérez (1999, p. 4):

\begin{abstract}
En las ideas de Dewey aflora con meridiana claridad que la escuela es una real institución social en la cual se deben concentrar todos los medios disponibles que contribuyan y posibiliten que el individuo exprese, con la mayor fuerza y alcance, las potencialidades biológicas y cognitivas que posee, o lo que es lo mismo, que el individuo llegue a desarrollar al máximo sus capacidades para luego proyectarlas en la sociedad de manera tal que contribuya a su desarrollo ulterior y al suyo propio. "El hombre se forma para vivir dentro de su medio social" decía este filósofo y pedagogo norteamericano, "como si la escuela fuera en la práctica una comunidad en miniatura, con un fuerte sentido democrático favorecedor de la colaboración y ayuda mutua entre los ciudadanos.
\end{abstract}

En el cuadro siguiente, se resumen descriptivamente, las va riables que definen al modelo pedagógico concomitante con el escolanovismo: TESIS:
"La acción educativa pretende que los intereses de los propios educandos la condicionen y le den
sentido"

BASE FILOSÓFICA:

Se apoya fundamentalmente en corrientes del movimiento racionalista: Kant; Hégel y las llamadas corrientes espiritualistas.

\title{
BASE HISTÓRICO-SOCIAL:
}

Pretende una real integración y participación del individuo en el sistema económico-social, a partir de la satisfacción de sus intereses. Convertir al individuo en partícipe y promotor del desarrollo social es la premisa básica.

\section{BASE PSICOLÓGICA:}

Se apoya básicamente en los aportes del paradigma cognitivista, cuyo eje central es destacar el protagonismo del individuo como sujeto del conocimiento.

MODELO DIDÁCTICO:

Para qué enseñar: Educar al alumno imbuyéndolo de la realidad inmediata, a partir de sus propios intereses.

Qué enseñar: Contenidos presentes en la realidad inmediata. Importancia de las destrezas y las actitudes.

Cómo enseñar: Metodología basada en el "descubrimiento espontáneo" por parte del alumno. Realización por parte del alumno de múltiples actividades (frecuentemente en grupos) de carácter abierto y flexible. Papel central y protagonista del alumno (que realiza gran diversidad de actividades) Rel. Alumno-docente: El papel del profesor es no directivo; coordina la dinámica general de la clase como líder social y afectivo.

Evaluación: Centrada en las destrezas y, en parte, en las actitudes. Atiende al proceso, aunque no de forma sistemática. Realizada mediante la observación directa y el análisis de trabajos de alumnos (sobre todo de grupos) 


\section{CONCLUSIONES}

Es claro, como hemos podido apreciar que la vigencia de los paradigmas pedagógicos históricos mantienen casi inalterable su gravitación en el entretegido simbólico del que los docentes nutren sus ideas y actitudes, configuradoras de las prácticas concretas. Las razones de ello son varias y desbordan las pretenciones del presente trabajo. Pero una cuestión sí es necesaria dejar en claro: la necesidad de prestar mayor atención en los procesos de formación y capacitación docente a este tema como una de las condiciones fundamentales a la hora de diseñar y elaborar los correspondientes dispositivos pedagógicodidácticos.

El reduccionismo técnico-instrumental en que se cae casi permanentemente tanto en la dinámica curricular de las instituciones formadoras docentes como en la variada y numerosa oferta de capacitación y perfeccionamiento, solo contribuye al sostenimiento de una educación que gravita a partir de la particular cocepción del sujeto pedagógico universal; sujeto al que la nueva configuración sociocultural de la sociedad postcapitalista ha extendido, hace bastante, su certificado de defunción.

\section{BIBLIOGRAFÍA}

Alfonso SÁNCHEZ, ILEANA R.; GONZÁleZ PÉREZ, TROADIO L. (1999) Tendencias pedagógicas contemporáneas. Recuperado el día 20 del mes de marzo del año de 2001 de www.monografias.com/trabajos6/tenpe/tenpe.shtml

BERGER P. y LUCKMANN T., (1979) La construcción social de la realidad. Buenos Aires: Amorrortu.

BERNSTEIN, BASIL. (1993) La estructura del discurso pedagógico. Madrid: Editorial Morata.

BIANCHETTI, R. G (1999) Una aproximación al análisis de las orientaciones políticas para la formación docente en el contexto de políticas de ajuste o de cómo se aplica el principio de la bomba de neutrones en educación. Revista Heuresis. Vol.2 (4), pags. 2 - 8 (versión electrónica) Recuperada el día 27 del mes de mayo del año 2000 de http://www2.uca.es/HEURESIS/heuresis99/v2n1.html

BOURDIEU, P. y PASSERON J. C. (1998) La reproducción: elementos para una teoría del sistema de enseñanza. México: Distribuciones Fontamara.

CABAlleRo, Z. B. (2001) Discurso pedagógico en tiempo de crisis: una aproximación a los años 1984 1990. Buenos Aires: Homo Sapiens Ediciones.

CANALES, M. (1996). Sociología de la vida cotidiana. Recuperado el día 27 del mes de mayo del año 2000 de http://www.uchile.cl/facultades/csociales/excerpta/canales.htm

CARUSO, M. y DuSSEL, I. (1995) De Sarmiento a los Simpsons. Buenos Aires: Editorial Kapelusz.

DAVINI, M. C. (1995) La formación docente en cuestión: política y pedagogía. Buenos Aires .Editorial Paidós.

De LELLA, C. (1999) Modelos y tendencias de la formación docente. Revista Iberoamericana de Educación; (19), pags. 5-12, enero-abril (versión electrónica) Recuperado el día 20 del mes de marzo del año 2001 de http://www.oei.es/cayetano.htm

ESNAOLA, G. A. (1996) Obstáculos epistemológicos en la formación docente. Revista Ensayos y Experiencias, año 3, (14), pags. 12-15, diciembre.

GARcía PÉREZ, F. F. (2000) Los modelos didácticos como instrumento de análisis y de intervención en la realidad educativa. Revista Bibliográfica de Geografía y Ciencias Sociales, 207, № 207, 18 de febrero de 2000 (versión electrónica). Recuperada el día 15 del mes de agosto del año 2000 de http://www.ub.es/geocrit/b3w-207.htm

GiBAJA, R. (1992) La cultura de la escuela. Creencias pedagógicas y estilos de enseñanza. Buenos Aires: Aique Grupo Editor

Hargreaves, A. (1994) Profesorado, cultura y posmodernidad. Madrid: Ediciones Morata.

HERnÁNDEZ, C. A. (1999) Aproximaciones a la discusión sobre el perfil del docente. Biblioteca Digital de la Organización de los Estados Iberoamericanos. Recuperada el día 18 del mes de julio del año 2000 de http://campus-oei.org/de/cah.htm 
JODELET, D. (1993). La representación social: fenómenos, concepto y teoria. En Moscovici, S. (comp.) Psicología Social II. Capítulo 13. Barcelona: Ediciones Paidós.

KAPLAN, CARINA V. (1997) La inteligencia escolarizada. Buenos Aires: Miño Dávila y Editores.

MARTIÑ́, R. (1989). Reflexiones sobre una crisis. En Fasce, J. y Martiñá, R. (comp.) Nosotros educadores. Segunda parte. Buenos Aires: Miño y Dávila Editores.

MORA MARTínEZ, M. (1997) El modelo de las representaciones sociales de Serge Moscovici. Recuperado el día 19 del mes de junio del año de 1999 de http://www.geocities.com/Paris/Rue/8759/vitalis.html, p. 2

PÉREZ SÁNCHEZ, C. N. (2000) La escuela frente a las desigualdades sociales. Apuntes sociológicos sobre el pensamiento docente. Revista Iberoamericana de Educación (23), mayo-agosto 2000 (versión electrónica) Recuperada el día 18 del mes de julio del año 2000 de http://www.campusoei.org/revista/rie23a06.htm

PINEAU, P. (1999) La pedagogía... la pedagogía entre la disciplina y la dispersión: una mirada desde la historia”. Recuperado el día 20 del mes de marzo del año de 2001 de http://www.iefrbrest.com.ar/pub06.htm

PIZAÑNA, E. D. (2001) Las creencias de los profesores, un campo para deliberar en los procesos de formación. Revista Acción Educativa, Universidad Autónoma de Sinaloa, Culiacán, México, volumen I, (1) Febrero, (versión electrónica) Recuperada el día 23 del mes de julio del año 2001 de http://www.campus-oei.org/revista/rie23a06.htm

PUIGRós, A. (1990). Sujetos, política y currículum en los orígenes del sistema educativo argentino. Buenos Aires: Editorial Galerna.

TAMARIT, J. (1994) Educar al soberano: crítica al iluminismo pedagógico de ayer y de hoy. Buenos Aires: Miño y Dávila Editores.

TEDESCO, J. C. (2001) Escuela y cultura: una relación conflictiva. Recuperado el día 22 del mes de marzo del año de 2002 de http://www.iipe-buenosaires.org.ar/pdfs/escuela y cultura.pdf

TENTI FANFANI, E. (1999) Saberes sociales y saberes escolares. Conferencia dictada en el Simposio Internacional de Educación, Saltillo, Coahuila, México, en el mes de junio de 1999. Recuperado el día 20 del mes de marzo del año de 2001 de http://pp.terra.com.mx/ /uisr/home-esp.htm

TERIG, F. y DIKER, G. (1997). La formación de maestros y profesores: hoja de ruta”. Buenos Aires: Editorial Paidós.

TONUCCI, F. (1996) La escuela no se cambia desde una normativa. Revista La Educación en Nuestras Manos, año 5, (41), pags. 23-25, mayo.

ZACCAGNINI, Mario (2000) ¿Desaprender para enseñar o aprendiendo a enseñar?. En Jolis, M. D. (comp.) Adolescentes en la escuela y en la universidad: que se dice y que se hace. Sección segunda, eje psicopedagógico. Buenos Aires: Editorial Lumen-Humanitas.

ZACCAGNiNi, Mario C. (2002) "Las representaciones sociales en la construcción del rol docente". Tesis de maestría; Universidad Nacional de Mar del Plata. Inédita. 